\title{
Measuring the forecast performance of GARCH and Bilinear-GARCH models in time series data
}

\author{
Akintunde Mutairu Oyewale, D. K. Shangodoyin, P. M Kgosi \\ Department of Statistics, University of Botswana, Botswana \\ Email address: \\ waleakintunde2004@yahoo.com(A. M. Oyewale)
}

\section{To cite this article:}

Akintunde Mutairu Oyewale, D. K. Shangodoyin, P. M Kgosi. Measuring the Forecast Performance of GARCH and Bilinear-GARCH Models in Time Series Data. American Journal of Applied Mathematics. Vol. 1, No. 1, 2013; pp. 17-23.

doi: 10.11648/j.ajam.20130101.14

\begin{abstract}
In most of the literature in time series modeling, generalized autoregressive conditional heterosceasticity (GARCH) models has been used as a traditional model to forecast both the economic and financial time series data. Though literature has shown that it is not suitable for non-linear time series. For this reason, this model was augmented with bilinear model in order to make it more relevant in forecasting both economic and financial time series data. After the augmentation, the new model called Bilinear-GARCH (BL-GARCH) shows a better performance based on performance measures indices, models variances and out-of-samples forecast performances. In term of these three criteria the new models outperformed the traditional or classical GARCH model. To drive home this point, these two models were illustrated with Botswana inflation rates data. We observed that the new model (BL-GARCH) outperformed the classical GARCH model.
\end{abstract}

Keywords: GARCH Models, BL-GARCH Models, Forecasting, Inflation Rates and Non-Linear

\section{Introduction}

Recent developments in financial econometrics require the use of model that will bring to the investor(s) high returns on their investments. In this context inflation rates play a very important role as these are major determinants in financial markets. The Generalization of ARCH model known as GARCH was introduced by Bollerslev (1986), which various researchers has extended. Deficiency of GARCH model was noted by many researchers like Hinich (1998), Liew, et.al.(2003), Lim et.al.(2005),Claudio and Jean (2011) and so many other researchers, they all concluded that GARCH model cannot capture non-linear aspect of the series adequately hence the need to find a more suitable model. An augmented GARCH model is an hybrid of the GARCH model formed by combining bilinear model with GARCH model (BL-GARCH). It allows us to capture asymmetries in the conditional mean and variance of financial and economic time series by means of interactions between past shocks and volatilities. The bilinear-GARCH models take into account variations between the independent variables as well as co-variations between the variables. This is very important in the study of financial market data where the covariance between independent variables may play a significant role in determining market volatility.

The remaining part of this paper is organized as follows: Section 2 covers the specification of GARCH models, estimation of the parameters of Bilinear-GARCH model (BL-GARCH), Section performance adequacy measurement 3, empirical illustration, identification of nonlinearity status of the series, estimation of classical GARCH and BL-GARCH models Section 4 Forecast performance and section 5: conclusion

\section{Specification of Generalized Autoregressive Conditional Heteroscedasticity Model}

The Generalized Autoregressive Conditional Heteroscedasticity Model (GARCH) was proposed by Bollerslev (1986). The specification of $\operatorname{GARCH}(p, q)$ is as follows:

let $\left(y_{t}\right)$ be the time series of an inflation rate return, then

$$
y_{t}=\sigma_{t} \varepsilon_{t} \text { and }
$$




$$
\begin{gathered}
\sigma_{t}^{2}=\alpha_{0}+\alpha_{1} y_{t-1}^{2}+\ldots \ldots+\alpha_{q} y_{t-q}^{2}+\beta_{2} \sigma_{t-1}^{2}+\ldots . .+\beta_{p} \sigma_{t-p}^{2} \\
\sigma_{t}^{2}=\alpha_{0}+\sum_{i=1}^{p} \alpha_{i} y_{t-1}^{2}+\sum_{j=1}^{q} \beta_{j} \sigma_{t-j}^{2}
\end{gathered}
$$

Where $\alpha_{0}>0, \alpha_{i} \geq 0$ and innovation sequence $\{\varepsilon\}_{i=-\infty}^{\infty}$ is independent and identically distributed (iid) with $E\left(\varepsilon_{0}\right)=0$ and $E\left(\varepsilon_{0}^{2}\right)=1$. The model described in equation (1) is used to parameterize financial time series and in particular foreign exchange.

To derive the variance of $y_{t}$ from the conventional expression given as:

$$
\begin{gathered}
\operatorname{Var}\left(y_{t}\right)=E\left(y_{t}^{2}\right)-\left(E\left(y_{t}\right)\right)^{2} \\
\left.E\left(y_{t}^{2}\right)=\alpha_{0}+\sum_{i=1}^{p} \alpha_{i}+\beta_{j}\right) E\left(y_{t-1}^{2}\right)-\sum_{j=1}^{q} \beta_{j} E\left(Z_{t-j}\right)+E\left(Z_{t}\right) \\
\alpha_{0}+E\left(y_{t}^{2}\right) \sum_{i=1}^{p}\left(\alpha_{i}+\beta_{j}\right)
\end{gathered}
$$

reduces to

$$
E\left(y_{t}^{2}\right)=\frac{\alpha_{0}}{1-\sum_{i=1}^{p}\left(\alpha_{i}+\beta_{j}\right)}
$$

Using (2) and (3) gives (4)

$$
\text { Thus } \operatorname{Var}\left(y_{t}\right)=\frac{\alpha_{0}}{1-\sum_{\mathrm{l}=1}^{\mathrm{p}}\left(\alpha_{\mathrm{i}}+\beta_{j}\right)} \forall \mathrm{i} \neq \mathrm{j}
$$

\subsection{Bilinear-GARCH Model (BL-GARCH)}

The mean and variance of augmented GARCH model are given as follows:

$$
\begin{gathered}
y_{t}=\sigma_{t} \varepsilon_{t}+\sum_{i=1}^{p} \sum_{j=i}^{q} \tau_{i j} y_{t-i} \varepsilon_{t-j} \\
y_{t}^{2}=\sigma_{t}^{2} \varepsilon_{t}^{2}+\tau_{I}^{2} y_{t-1}^{2} \varepsilon_{t-1}^{2} \\
E\left(y_{t}^{2}\right)=E\left(\sigma_{t}^{2} \varepsilon_{t}^{2}\right)+\tau_{i}^{2} E\left(y_{t-1}^{2}\right)
\end{gathered}
$$$$
\text { That is, } \quad E\left(y_{t}^{2}\right)=\frac{E\left(\sigma_{t}^{2}\right)}{\left(1-\tau_{i}^{2}\right)}
$$

$$
\text { Since } E\left(\sigma_{t}^{2}\right)=E\left[\alpha_{0}+\sum \alpha_{i} y_{t-1}^{2}+\sum \beta_{j} \sigma_{t-1}^{2}\right]
$$

$$
E\left(y_{t}^{2}\right)=\frac{E\left(\sigma_{t}^{2}\right)}{\left(1-\tau_{i}^{2}\right)}=\frac{\alpha_{0}+\sum \alpha_{i} \sigma_{t-1}^{2}+\sum \beta_{j} \sigma_{t-1}^{2}}{1-\tau_{i}^{2}}
$$

$$
\operatorname{Var}(B L-G A R C H)
$$

$$
=\frac{\alpha_{0}+\sum \alpha_{i} \sigma_{t-1}^{2}+\sum \beta_{j} \sigma_{t-1}^{2}}{1-\tau_{i}^{2}}-\sigma_{\varepsilon}^{4}\left(\sum \tau_{i}\right)^{2} \quad \forall \mathrm{i}=\mathrm{j}
$$

\subsection{Model Evaluation Statistics Indices}

$$
\tilde{y}_{t+h}^{2}=\alpha_{0}(1)+\sum_{i=1}^{p} \alpha_{i} y_{t-i}^{2}(h)+\sum_{j=i}^{q} \beta_{j} y_{t-j}^{2}(h)
$$

The square root of equation (8) shall be used as a forecast function of GARCH models while the equation (9) below shall be used as a forecast function of BL-GARCH

$$
\tilde{y}_{t}^{2}(h)=\alpha_{0}+\sum_{i=1}^{p} \alpha_{i} y_{t-i}^{2}(h)+\sum_{j=i}^{q} \beta_{j} y_{t-j}^{2}(h)+\sum_{i=1}^{p} \sum_{j=1}^{q} \mathrm{~T}_{i j}^{2} y_{t+j}^{2}(h)
$$

We shall compare the forecast performance of equations (8) and (9) using the following

\subsection{Performance Adequacy Measures}

Several error indices are commonly used in model evaluation. These include mean absolute error (MAE), root mean square error (RMSE), mean absolute deviation (MAD), mean absolute precision error (MAPE) and THEIL $U$. These indices are valuable because they indicate error in the units (or squared units) of the constituent of interest, which aids in analysis of the results. RMSE, MAE, MAPE, MAD and Theil $U$ values of 0 indicate a perfect fit. Singh et al. (2004) state that RMSE and MAE values less than half the standard deviation of the measured data may be considered low and that either is appropriate for model evaluation.

$$
\text { 1. } R M S E=\sqrt{\left\{T^{-1} \sum_{t=1}^{T}\left(Y_{t}-\hat{Y}_{t}\right)\right\}}
$$

2. $M A E=T^{-1} \sum_{t=1}^{T}\left|Y_{t}-\hat{Y}_{t}\right|$

3. $M A D=T^{-1} \sum_{t=1}^{T}\left(Y_{t}-\overline{Y_{t}}\right)$

4. $M A P E=T^{-1} \sum_{t=1}^{T}\left|\frac{Y_{t}-\hat{Y}_{t}}{Y_{t}}\right| X 100$ 


$$
\text { 5. THEIL } U=\frac{\sqrt{T^{-1} \sum_{i=1}^{T}\left(X_{t}-\hat{X}_{t}\right)^{2}}}{\sqrt{T^{-1} X_{t}^{2}}+\sqrt{T^{-1} \hat{X}_{t}^{2}}}
$$

If the forecast error values are smaller, we say the forecast performance is good otherwise it is bad. If the results are not consistent among the first three we choose the MAPE to be the benchmark.

\section{Results and Discussion}

\subsection{Checking the Stationarity of the Series}

Before using any series, there is need to determine the stationarity of such series otherwise the whole exercise will be a nullity and as a result of this, three important methods are used in this paper to determine the stationarity of the series. These are graph, correlogram and unit root test.

Figure1 shows evidence of non-stationarity of the series, since volatile values are evident and these do not fluctuate around a constant mean.

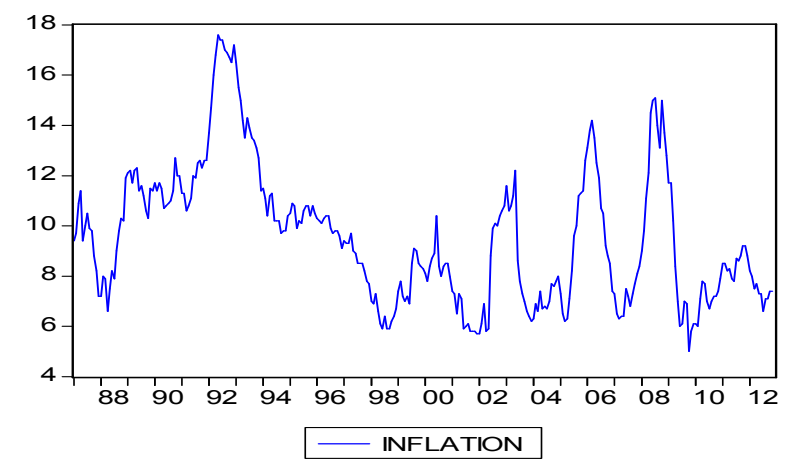

Figure 1. Line graph of the leveled Botswana inflation rates

We therefore transform the non-stationary series using the following formula:

$$
R_{t}=\ln \left\{\frac{y_{t}}{y_{t-1}}\right\} * 100
$$

After the transformation of the data, the new time series plot is shown below. The plot indicated that the mean of the series is now constant and as such we assume it is stationary.

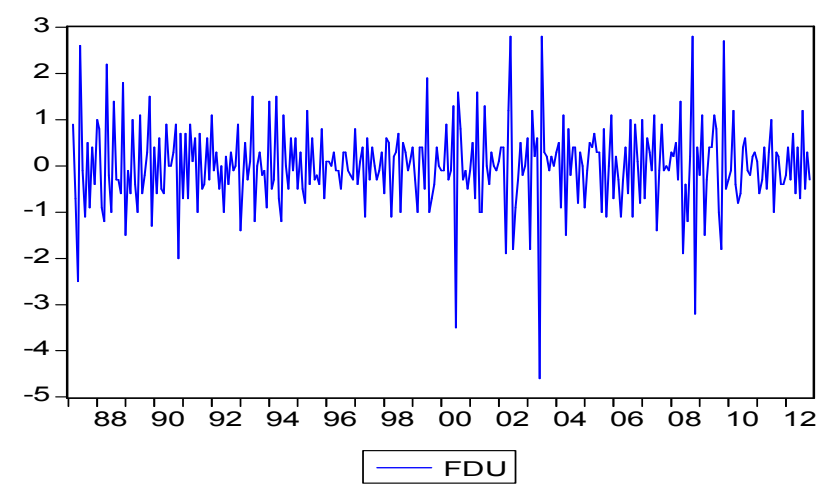

Figure 2. Line graph of the first difference of Botswana inflation rates

The results on the correlogram of the leveled for the series (as shown in table1 below) shows stronger evidence of non-stationarity since its autocorrelation coefficient function (ACF) of the residuals does not quickly decay to zero. it seems this series is not stationary.

So also the examination of correlogram of the first difference shows that there is no persistent trend and its values fluctuate around a constant mean of zero. hence this is suggesting that the exchange rate series is stationary

The table below shows that the result of Augmented Dickey-Fuller test on inflation rates series. since the statistic value for $\mathrm{ADF}$ test is greater than their corresponding critical values, so we do not reject the null hypothesis of the presence of unit root in the series and therefore conclude that the exchange rate is not stationary.

\begin{tabular}{|c|c|c|c|c|c|c|}
\hline \multicolumn{7}{|c|}{ Sample: 1987M01 2012M12 } \\
\hline \multicolumn{7}{|c|}{ Included observations: 311} \\
\hline Autocorrelation & Partial Correlation & & $\mathrm{AC}$ & $\mathrm{PAC}$ & Q-Stat & Prob \\
\hline$|* * * * * * *|$ & $|* * * * * * *|$ & 1 & 0.966 & 0.966 & 292.72 & 0.000 \\
\hline$|* * * * * * *|$ & $* *||$. & 2 & 0.917 & -0.220 & 557.78 & 0.000 \\
\hline$|* * * * * * *|$ & $*||$. & 3 & 0.864 & -0.069 & 793.50 & 0.000 \\
\hline||$^{* * * * * * \mid}$ & $*||$. & 4 & 0.802 & -0.133 & 997.32 & 0.000 \\
\hline||$^{* * * * * * \mid}$ & $*||$. & 5 & 0.732 & -0.117 & 1167.7 & 0.000 \\
\hline||$^{* * * * *} \mid$ &.$||$. & 6 & 0.661 & -0.012 & 1307.2 & 0.000 \\
\hline||$^{* * * * *} \mid$ &.$||$. & 7 & 0.592 & -0.005 & 1419.3 & 0.000 \\
\hline.$|* * * *|$ & $*||$. & 8 & 0.517 & -0.113 & 1505.3 & 0.000 \\
\hline.$|* * *|$ &.$||$. & 9 & 0.446 & 0.023 & 1569.4 & 0.000 \\
\hline.$|* * *|$ & .1 .1 & 10 & 0.377 & -0.028 & 1615.5 & 0.000 \\
\hline$.\left.\right|^{* *} \mid$ &.$||$. & 11 & 0.311 & -0.020 & 1646.9 & 0.000 \\
\hline
\end{tabular}

Table 1. Leveled Correlogram for Botswana inflation rates 


\begin{tabular}{|c|c|c|c|c|c|c|}
\hline.$|* *|$ &.$||$. & 12 & 0.246 & -0.035 & 1666.6 & 0.000 \\
\hline$.\left.\right|^{* *} \mid$ & $.\left.\right|^{* * *} \mid$ & 13 & 0.213 & 0.435 & 1681.4 & 0.000 \\
\hline$.\left.\right|^{*} \mid$ & $*||$. & 14 & 0.190 & -0.061 & 1693.2 & 0.000 \\
\hline$.\left.\right|^{*} \mid$ &.$||$. & 15 & 0.174 & 0.048 & 1703.1 & 0.000 \\
\hline$. *^{*} \mid$ &.$||$. & 16 & 0.165 & -0.017 & 1712.1 & 0.000 \\
\hline$. *^{*} \mid$ & $*||$. & 17 & 0.161 & -0.087 & 1720.7 & 0.000 \\
\hline$. *^{*} \mid$ &.$||$. & 18 & 0.159 & -0.031 & 1729.1 & 0.000 \\
\hline$.\left.\right|^{*} \mid$ &.$||$. & 19 & 0.157 & 0.026 & 1737.3 & 0.000 \\
\hline$.\left.\right|^{*} \mid$ &.$||$. & 20 & 0.164 & 0.027 & 1746.3 & 0.000 \\
\hline$. *^{*} \mid$ & $.\left.\right|^{*} \mid$ & 21 & 0.176 & 0.102 & 1756.7 & 0.000 \\
\hline$. *^{*} \mid$ & $*||$. & 22 & 0.189 & -0.067 & 1768.7 & 0.000 \\
\hline$.\left.\right|^{* *} \mid$ & $.\left.\right|^{*} \mid$ & 23 & 0.207 & 0.120 & 1783.2 & 0.000 \\
\hline$.\left.\right|^{* *} \mid$ & $.\left.\right|^{*} \mid$ & 24 & 0.236 & 0.069 & 1802.0 & 0.000 \\
\hline$.\left.\right|^{* *} \mid$ & $.||^{* *} \mid$ & 25 & 0.268 & 0.286 & 1826.5 & 0.000 \\
\hline$.\left.\right|^{* *} \mid$ &.$||$. & 26 & 0.300 & -0.018 & 1857.3 & 0.000 \\
\hline.$|* * *|$ &.$||$. & 27 & 0.329 & -0.019 & 1894.5 & 0.000 \\
\hline||$^{* * *} \mid$ &.$||$. & 28 & 0.357 & -0.017 & 1938.2 & 0.000 \\
\hline$.\left.\right|^{* * *} \mid$ & $* *||$. & 29 & 0.374 & -0.234 & 1986.5 & 0.000 \\
\hline$|* * *|$ & $*||$. & 30 & 0.386 & -0.060 & 2038.0 & 0.000 \\
\hline||$^{* * *} \mid$ &.$||$. & 31 & 0.393 & -0.029 & 2091.8 & 0.000 \\
\hline||$^{* * *} \mid$ &.$||$. & 32 & 0.397 & 0.026 & 2146.7 & 0.000 \\
\hline||$^{* * *} \mid$ & $.\left.\right|^{*} \mid$ & 33 & 0.396 & 0.118 & 2201.5 & 0.000 \\
\hline||$^{* * *} \mid$ & $*||$. & 34 & 0.387 & -0.147 & 2254.2 & 0.000 \\
\hline||$^{* * *} \mid$ &.$||$. & 35 & 0.369 & -0.010 & 2302.3 & 0.000 \\
\hline.$|* * *|$ &.$||$. & 36 & 0.341 & -0.034 & 2343.5 & 0.000 \\
\hline
\end{tabular}

Table 2. First difference Botswana inflation rates

\begin{tabular}{|c|c|c|c|c|c|c|}
\hline \multicolumn{7}{|c|}{ Sample: 1987M01 2012M12 } \\
\hline \multicolumn{7}{|c|}{ Included observations: 310} \\
\hline Autocorrelation & Partial Correlation & & $\mathrm{AC}$ & PAC & Q-Stat & Prob \\
\hline$.\left.\right|^{*} \mid$ & $.\left.\right|^{*} \mid$ & 1 & 0.171 & 0.171 & 9.1256 & 0.003 \\
\hline$.\left.\right|^{*} \mid$ &.$||$. & 2 & 0.070 & 0.043 & 10.686 & 0.005 \\
\hline$\left.\right|^{*} \mid$ & $.\left.\right|^{*} \mid$ & 3 & 0.133 & 0.118 & 16.235 & 0.001 \\
\hline$.\left.\right|^{*} \mid$ & $.\left.\right|^{*} \mid$ & 4 & 0.127 & 0.088 & 21.355 & 0.000 \\
\hline.$||$. &.$||$. & 5 & 0.028 & -0.017 & 21.607 & 0.001 \\
\hline.$||$. &.$||$. & 6 & 0.013 & -0.012 & 21.658 & 0.001 \\
\hline$.\left.\right|^{*} \mid$ &.$||$. & 7 & 0.071 & 0.049 & 23.270 & 0.002 \\
\hline.$||$. & $*||$. & 8 & -0.048 & -0.082 & 24.011 & 0.002 \\
\hline$*||$. &.$||$. & 9 & -0.065 & -0.054 & 25.383 & 0.003 \\
\hline.$||$. &.$||$. & 10 & -0.023 & -0.013 & 25.551 & 0.004 \\
\hline.$||$. &.$||$. & 11 & -0.018 & -0.007 & 25.657 & 0.007 \\
\hline$* * * *||$. & $* * * *||$. & 12 & -0.473 & -0.472 & 98.168 & 0.000 \\
\hline$*||$. &.$||$. & 13 & -0.150 & 0.006 & 105.46 & 0.000 \\
\hline$*||$. & $*||$. & 14 & -0.104 & -0.068 & 109.01 & 0.000 \\
\hline$*||$. &.$||$. & 15 & -0.123 & -0.003 & 113.96 & 0.000 \\
\hline$*||$. & $.\left.\right|^{*} \mid$ & 16 & -0.059 & 0.084 & 115.12 & 0.000 \\
\hline.$||$. & .1 .1 & 17 & -0.043 & 0.005 & 115.72 & 0.000 \\
\hline.$||$. & .1 .1 & 18 & -0.038 & -0.019 & 116.21 & 0.000 \\
\hline$*||$. & .1 .1 & 19 & -0.116 & -0.044 & 120.66 & 0.000 \\
\hline
\end{tabular}




\begin{tabular}{|c|c|c|c|c|c|c|}
\hline$*||$. & $* 1.1$ & 20 & -0.068 & -0.095 & 122.19 & 0.000 \\
\hline.$||$. &.$||$. & 21 & 0.003 & 0.002 & 122.19 & 0.000 \\
\hline.$||$. &.$||$. & 22 & -0.050 & -0.056 & 123.04 & 0.000 \\
\hline$*||$. & $*||$. & 23 & -0.111 & -0.084 & 127.21 & 0.000 \\
\hline.$||$. & $* *||$. & 24 & -0.015 & -0.263 & 127.29 & 0.000 \\
\hline.$||$. &.$||$. & 25 & 0.030 & 0.010 & 127.59 & 0.000 \\
\hline$.\left.\right|^{*} \mid$ &.$||$. & 26 & 0.073 & 0.037 & 129.41 & 0.000 \\
\hline.$||$. &.$||$. & 27 & 0.034 & -0.014 & 129.81 & 0.000 \\
\hline.$||$. & $.\left.\right|^{*} \mid$ & 28 & 0.051 & 0.104 & 130.70 & 0.000 \\
\hline.$||$. &.$||$. & 29 & 0.005 & -0.037 & 130.71 & 0.000 \\
\hline.$||$. &.$||$. & 30 & 0.020 & 0.001 & 130.85 & 0.000 \\
\hline.$||$. &.$||$. & 31 & 0.048 & -0.033 & 131.66 & 0.000 \\
\hline.$||$. & $*||$. & 32 & 0.060 & -0.060 & 132.93 & 0.000 \\
\hline$.\left.\right|^{*} \mid$ & $.\left.\right|^{*} \mid$ & 33 & 0.090 & 0.095 & 135.76 & 0.000 \\
\hline.$|*|$ &.$||$. & 34 & 0.103 & 0.041 & 139.52 & 0.000 \\
\hline$.\left.\right|^{*} \mid$ & $.\left.\right|^{*} \mid$ & 35 & 0.177 & 0.098 & 150.58 & 0.000 \\
\hline.$||$. & $*||$. & 36 & 0.063 & -0.166 & 151.97 & 0.000 \\
\hline
\end{tabular}

Table 3.

\begin{tabular}{|c|c|c|c|}
\hline \multicolumn{3}{|c|}{ Null Hypothesis: INFLATION has a unit root } & \\
\hline \multicolumn{4}{|l|}{ Exogenous: Constant } \\
\hline \multicolumn{4}{|c|}{ Lag Length: 12 (Automatic based on SIC, MAXLAG=15) } \\
\hline \multirow{2}{*}{\multicolumn{2}{|c|}{ Augmented Dickey-Fuller test statistic }} & t-Statistic & Prob.* \\
\hline & & -2.186148 & 0.2119 \\
\hline \multirow[t]{3}{*}{ Test critical values: } & $1 \%$ level & -3.452141 & \\
\hline & $5 \%$ level & -2.871029 & \\
\hline & $10 \%$ level & -2.571897 & \\
\hline
\end{tabular}

Table 4. first difference Augmented Dickey-Fuller test statistic

\begin{tabular}{|c|c|c|c|}
\hline \multicolumn{4}{|c|}{ Null Hypothesis: D(INFLATION) has a unit root } \\
\hline \multicolumn{4}{|l|}{ Exogenous: Constant } \\
\hline \multicolumn{4}{|c|}{ Lag Length: 11 (Automatic based on SIC, MAXLAG=15) } \\
\hline \multirow{2}{*}{\multicolumn{2}{|c|}{ Augmented Dickey-Fuller test statistic }} & t-Statistic & Prob.* \\
\hline & & -8.467909 & 0.0000 \\
\hline \multirow[t]{3}{*}{ Test critical values: } & $1 \%$ level & -3.452141 & \\
\hline & $5 \%$ level & -2.871029 & \\
\hline & $10 \%$ level & -2.571897 & \\
\hline
\end{tabular}

\subsection{Estimation of Classical GARCH Model}

To generate parameter estimates for the GARCH model, we used E-view to analyzed differenced data for the study as follows:
Based on tables 5 the estimated $\operatorname{GARCH}(1,1)$ model are obtained for the series as follows:

$y_{\text {Botswana Inflation }}=\sigma_{t} \varepsilon_{t}$ where $\sigma_{t}$ and $\varepsilon_{t}$ are obtainable from the fitted model:

$$
y_{y_{\text {Botswana Infation }}}=0.995353 y_{t-1}+\varepsilon_{t} \text { and } \sigma_{t}^{2}=0.386450+1.010397 \varepsilon_{t-1}^{2}-0.040497 * \sigma_{t-1}^{2}
$$


Table 5. GARCH model estimates for Botswana inflation rates

\begin{tabular}{|c|c|c|c|c|}
\hline \multicolumn{5}{|c|}{ Dependent Variable: INFLATION } \\
\hline \multicolumn{5}{|c|}{ Included observations: 311 after adjustments } \\
\hline \multicolumn{5}{|c|}{ Convergence achieved after 291 iterations } \\
\hline \multicolumn{5}{|c|}{$\mathrm{GARCH}=\mathrm{C}(2)+\mathrm{C}(3)^{*} \mathrm{RESID}(-1)^{\wedge} 2+\mathrm{C}(4)^{*} \mathrm{GARCH}(-1)$} \\
\hline & Coefficient & Std. Error & z-Statistic & Prob. \\
\hline \multirow[t]{2}{*}{ DATE } & 0.003989 & $3.52 \mathrm{E}-05$ & 113.4602 & 0.0000 \\
\hline & Variance $\mathrm{Ec}$ & & & \\
\hline $\mathrm{C}$ & 0.386450 & 0.110917 & 3.484122 & 0.0005 \\
\hline $\operatorname{RESID}(-1)^{\wedge} 2$ & 1.010397 & 0.281102 & 3.594408 & 0.0003 \\
\hline GARCH(-1) & -0.040497 & 0.052512 & -0.771194 & 0.4406 \\
\hline T-DIST. DOF & 414.8035 & 18607.56 & 0.022292 & 0.9822 \\
\hline R-squared & -0.345878 & Mean dep & & 9.540836 \\
\hline Adjusted R-squared & -0.363471 & S.D. depe & & 2.699959 \\
\hline S.E. of regression & 3.152682 & Akaike in & & 4.131431 \\
\hline Sum squared resid & 3041.457 & Schwarz c & & 4.191556 \\
\hline Log likelihood & -637.4375 & Durbin-W & & 0.049754 \\
\hline
\end{tabular}

\subsection{Estimation of Augmented GARCH Model}

Estimation of parameters here was done here in two stages as the standard deviation obtained from classical GARCH was used to obtain the parameters of augmented GARCH models. The reduced form in equation (10) was estimated by making use of Bilinear $(1,1)$ the reason for the choice of bilinear $(1,1)$ was due to the fact that few parameters make the models to be parsimonious; from where sets of data were generated and OLS applied and the following results were obtained for the series By using the values generated in table 6 the BL-GARCH fitted for the series is as follows:

$$
\text { Naira: } y_{t}=\sigma_{t} \varepsilon_{t}+\underset{(0.000044)}{0.087210} y_{t-1} \varepsilon_{t-1}
$$

with variance of the model 0.855926982 (16)

Table 6. Bilinear-GARCH model for Botswana inflation rates

\begin{tabular}{|c|c|c|c|c|}
\hline \multicolumn{5}{|c|}{ Dependent Variable: $y_{t}-\sigma_{t} \varepsilon_{t}=\mathrm{ACMINFIT}$ (Botswana inflation rates ) } \\
\hline \multicolumn{5}{|l|}{$\mathrm{ACMINFIT}=\mathrm{C}(1) * \mathrm{ZT}$} \\
\hline \multicolumn{5}{|c|}{$\mathrm{GARCH}=\mathrm{C}(2)+\mathrm{C}(3)^{*} \mathrm{RESID}(-1)^{\wedge} 2+\mathrm{C}(4)^{*} \mathrm{GARCH}(-1)$} \\
\hline & Coefficient & Std. Error & z-Statistic & Prob. \\
\hline \multirow[t]{2}{*}{$\mathrm{C}(1)$} & 0.030362 & 0.000722 & 42.02450 & 0.0000 \\
\hline & Variance Ec & & & \\
\hline $\mathrm{C}$ & 0.198439 & 0.069874 & 2.839955 & 0.0045 \\
\hline $\operatorname{RESID}(-1)^{\wedge} 2$ & 0.934091 & 0.265796 & 3.514319 & 0.0004 \\
\hline GARCH(-1) & 0.059534 & 0.077003 & 0.773148 & 0.4394 \\
\hline T-DIST. DOF & 2067.880 & 402682.1 & 0.005135 & 0.9959 \\
\hline R-squared & 0.346199 & Mean dep & & 1.564199 \\
\hline Adjusted R-squared & 0.337624 & S.D. depe & & 2.716843 \\
\hline S.E. of regression & 2.211143 & Akaike in & & 3.756116 \\
\hline Sum squared resid & 1491.192 & Schwarz c & & 3.816383 \\
\hline Log likelihood & -577.1980 & Durbin-W & & 0.058222 \\
\hline
\end{tabular}

\section{Forecast Performance}

\subsection{Forecast Evaluation Indices}

Botswana inflation rates were subjected to all performance evaluation indices cross tabulated with GARCH and

Bilinear-GARCH models, it is clear from here that Bilinear-GARCH is far better than GARCH model as it produced the minimum of all this indices as seen in table (7) above.

Next we looked at the variance of the two models. A model that gives the minimum variance is adjudged as the better model. For instance from the table below (8). Bilinear-GARCH gave the minimum variance of 4.8892 compared to GARCH model which gave the variance of 9.9394 as shown below: 
Table 7. Forecast indices for the models

\begin{tabular}{lll}
\hline model/indices & GARCH & BL- GARCH \\
\hline MSE & 3.1272 & 2.1932 \\
MAE & 2.3533 & 1.8188 \\
MAPE & 22.2050 & 18.6544 \\
THEIL-U & 0.1748 & 0.3966 \\
BIAS PROPORTION & 0.2501 & 0.1156 \\
U-VAR PROPORTION & 0.9266 & 0.8842 \\
U-COV PROPORTION & 0.0232 & 0.0002 \\
\hline
\end{tabular}

Table 8. Variances of the models

\begin{tabular}{lll}
\hline Model & GARCH & BL-GARCH \\
\hline Variance & 9.9394 & 4.8892 \\
\hline
\end{tabular}

Forecast performance of fitted GARCH $(1,1)$ and BLGARCH $(1,1)$ models for the inflation rates has investigated shows that out-of-sample forecast performance for classical GARCH model for the inflation rate series under consideration failed to produced good forecast, whereas the BL-GARCH performed very well as showing in the following tables (9) and (10) below:

Table 9. out-of-sample forecast performance for GARCH (2012)

\begin{tabular}{|c|c|c|c|c|c|c|c|c|c|c|c|c|}
\hline Date & Jan. & Feb. & Mar. & Apr. & May & June & July & Aug & Sept. & Oct. & Nov. & Dec. \\
\hline Actual & 8.8 & 8.2 & 8.0 & 7.5 & 7.7 & 7.3 & 7.3 & 6.6 & 7.1 & 7.1 & 7.4 & 7.4 \\
\hline Forecast & 6.03 & 6.03 & 6.03 & 6.03 & 6.03 & 6.03 & 6.03 & 6.03 & 6.03 & 6.03 & 6.03 & 6.03 \\
\hline
\end{tabular}

Table 10. Out-of-samples forecast performance for Bilinear-GARCH (2012)

\begin{tabular}{|c|c|c|c|c|c|c|c|c|c|c|c|c|}
\hline Date & Jan. & Feb. & Mar. & Apr. & May & June & July & Aug & Sept. & Oct. & Nov. & Dec. \\
\hline Actual & 8.8 & 8.2 & 8.0 & 7.5 & 7.7 & 7.3 & 7.3 & 6.6 & 7.1 & 7.1 & 7.4 & 7.4 \\
\hline Forecast & 8.83 & 8.35 & 8.02 & 7.68 & 7.89 & 7.78 & 7.48 & 6.71 & 7.13 & 7.13 & 7.42 & 7.42 \\
\hline
\end{tabular}

\subsection{Forecast Evaluation}

Looking at table (9) and (10) which are the tables of outof-samples forecast performance for the two models under study, it is evident that the forecast performance of classical GARCH model is not good as it gave constant values which under estimated the actual values, however, the forecast performance of Bilinear-GARCH model gave result that is comparable to the actual data. This shows that BL-GARCH outperformed classical GARCH model and as such recommended for would-be researcher(s).

\section{Conclusion}

This paper compared the two models used in measuring the forecast performance of Botswana inflation rates. The models are GARCH and Bilinear-GARCH, Monthly inflation rates of Botswana from 1978 to 2012 were used for empirical illustration. We examined the stationarity of the model using three tests (graph, correlogram and unit root), all these tests indicated that the series were not stationary. To ensure that the series are stationary we transformed the data and after the transformation the series was stationary. GARCH $(1,1)$ and Bilinear-GARCH $(1,1)$ was fitted to the model and there after we examined the forecast performance for the two models, in term of forecast performance indices and measurement of models variances Bilinear-GARCH model outperformed classical GARCH model. We also compared the out-of-sample forecast performance for the two models; Bilinear-GARCH also gave better forecast performance as seen from tables (9) and (10) above. So for would be forecasters, investors and other policy analysts the use of Bilinear-GARCH is recommended as it gave an excellent forecast compared to classical GARCH model

\section{References}

[1] Anderson T.G.,Bollerslev,T. and Diebold, F.X. (2003) parametric and non parametric volatility measurement. In handbook of financial Econometrics (eds Y. AIT-SAHALIA and L.P Hansen). Amsterdam: North-Holland press.

[2] Anderson T. W. (2003) Estimation for Autoregressive Moving Average Models in the Time and Frequency Domains. The Ann. of Stat. Vol 5 No. 5, 842-865

[3] Anderson, T. W. (1977) The Statistical Analysis of Time Series, New York and London Wiley.

[4] Bonilla, C., Romero-Meza, R. and Hinich, M. J. (2006) Episodic nonlinearities in the Latin American stock market indices, Applied Economics Letters, 13, 195-9.

[5] Box, G. E. P. and G.M. Jenkins (1970) Time Series, Forecasting and Control. Holden-Day: San Francisco.

[6] Bruni, C., Dupillo, G. and Koch, G. (1974) Bilinear Systems: An Appealing Class of Nearly Linear System in Theory and Application. IEEE Trans. Auto Control Ac-19, 334-338.

[7] Engle, R.F. (1982). Autoregressive Conditional Heteroscedasticity with estimates of variance of United Kingdom inflation. Econometrica, 50(4), 987-1007. Baillie, R.

[8] Nelson, D.B. (1991). Conditional heteroscedasticity in asset returns: A new approach.

[9] Econometrica, 59(2), 347-370.

[10] Poon, S.H., Granger, C.W.J. (2003). Forecasting financial market volatility: A review.

[11] Journal of Economic Literature, 41(2), 478-539(62). 